\title{
Cardiac surgery in Colombia: History, advances, and current perceptions of training
}

Eric E. Vinck, MD

\footnotetext{
From the Division of Thoracic Surgery Research, Department of Surgery, El Bosque University, Fundación Cardioinfantil; Dr Horacio Oduber Hospitaal, Oranjestad, Aruba.

Disclosures: Author has nothing to disclose with regard to commercial support.

Received for publication Aug 25, 2019; revisions received Sept 13, 2019; accepted for publication Sept 16, 2019; available ahead of print Nov 4, 2019

Address for reprints: Eric E. Vinck, MD, Av Cra 9 No 131 A-02, Bogotá, Colombia (E-mail: evinck518@gmail com).

J Thorac Cardiovasc Surg 2020;159:2347-52

$0022-5223 / \$ 36.00$

Copyright (C) 2019 by The American Association for Thoracic Surgery

https://doi.org/10.1016/j.jtcvs.2019.09.079
}

\section{EARLY BEGINNINGS IN HEART SURGERY}

In Colombia, cardiac surgery, or cardiovascular surgery, is a subspecialty of general surgery apart from general thoracic and vascular surgery. Cardiovascular surgeons in Colombia treat surgical pathologies of the heart and intrathoracic great vessels, and general thoracic surgeons treat pathologies of the pleura, lung, diaphragm, and chest wall.

The history of cardiac surgery in Colombia begins with Pompilio Martínez, who performed the country's first cardiac suture for a penetrating heart injury in Bogota in 1914. ${ }^{1}$ Later, in 1948, American surgeon Dr George Humphreys would visit the country's capital and perform a variety of thoracic procedures, including some minor congenital cardiac surgeries. In 1954, Colombian surgeon Dr. José Félix Patiño, at that time attending Yale, presented a concept to Dr. William Glenn for a superior vena cava-toright pulmonary artery shunt to bypass a defective right heart. In 1958, Glenn performed this procedure in New Haven, and a year later Patiño performed it in Bogota. ${ }^{2}$ Also in 1958, Dr Antonio Ramírez reported a series of 47 cardiac procedures performed under superficial hypothermia. In 1966, in Medellin, Drs Alberto Villegas and Mario Montoya began performing the country's first coronary artery bypass surgeries, as well as arrhythmia surgeries. In 1968 in Medellin, Dr Antonio Ramírez performed the first mitral valve replacement using extracorporeal circulatory technology, and later the first aortic arch replacement. ${ }^{3,4}$ In 1981, Dr Aminta Capasso became the first female cardiovascular surgeon in the country. Table 1 lists historic events in Colombian cardiac surgery.

\section{ADVANCES IN CARDIAC SURGERY: TRANSPLANT AND ROBOTIC SURGERY}

In 1985, Colombia was facing one of the darkest years in its history. During this year, 2 events affected the country significantly. First, guerilla forces were responsible for the

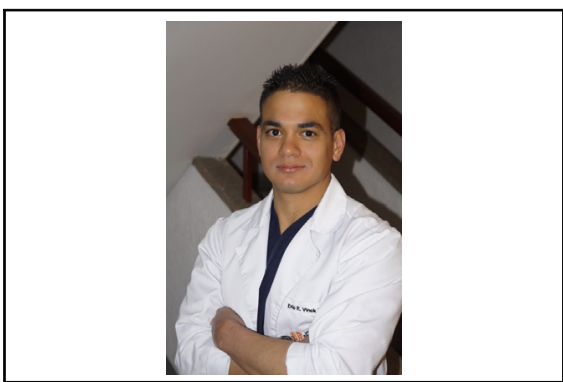

Eric E. Vinck, MD

Central Message

Standardizing international cardiac surgery training is a challenging process. Here I describe how cardiac surgery residency is organized in Colombia and discuss current perceptions of training.

Perspective

Cardiac surgery training varies from country to country, and differences in curriculum designs and track structures result in variations in training quality. To maintain international training standards, it is imperative to describe program curricula in different countries to identify pitfalls and improve the quality of cardiac surgery residency.

justice hall takeover and massacre costing the lives of more than 90 Colombians, including others who went missing. Second, a small rural town called Armero was completely wiped out by a volcanic eruption, taking the lives of more than 20,000 Colombians. As a result, the country was in mourning and heartbroken. Hope was soon restored when on the morning of December 1, 1985, Dr Alberto Villegas and his team of transplant surgeons in Medellin performed the country's first heart transplantation. On this Sunday morning at 8:23 am at Hospital San Vicente de Paúl, surgeons completed harvesting, and simultaneously, surgeons at the Clínica Cardiovascular Santa Maria began working on the recipient, a 36-year-old male construction worker. With impressive synchronization, transplantation began at 9:00 am. A few hours later, at 11:45 am, the procedure was over, and Colombia's first transplanted heart began beating spontaneously. ${ }^{3,4}$ This first 
TABLE 1. Colombian cardiovascular surgery timetable

\begin{tabular}{|c|c|c|}
\hline Event & Year & Location \\
\hline First cardiac suture for trauma & 1914 & Bogota \\
\hline First congenital cardiac procedures & 1948 & Bogota \\
\hline $\begin{array}{l}\text { First series of cardiac surgeries under } \\
\text { superficial hypothermia }\end{array}$ & 1958 & Medellin \\
\hline Glenn-Patiño procedure & 1959 & Bogota \\
\hline $\begin{array}{l}\text { First coronary artery bypass graft } \\
\text { surgery }\end{array}$ & 1966 & Medellin \\
\hline First mitral valve replacement & 1968 & Medellin \\
\hline First female cardiac surgeon & 1981 & Bogota \\
\hline First heart transplant & 1985 & Medellin \\
\hline $\begin{array}{l}\text { First off-pump coronary artery bypass } \\
\text { graft surgery (beating heart } \\
\text { surgery) }\end{array}$ & 1994 & Medellin \\
\hline $\begin{array}{l}\text { First heart transplant department in } \\
\text { Bogota }\end{array}$ & 1996 & Bogota \\
\hline $\begin{array}{l}\text { Cardiac surgeons perform the } \\
\text { country's first lung transplant }\end{array}$ & 1997 & Medellin \\
\hline $\begin{array}{l}\text { Cardiac surgeons perform the } \\
\text { country's first bilateral lung } \\
\text { transplant }\end{array}$ & 1999 & Medellin \\
\hline $\begin{array}{l}\text { First transcatheter aortic valve } \\
\text { replacement procedure }\end{array}$ & 2008 & Cali \\
\hline $\begin{array}{l}\text { First simultaneous heart and lung } \\
\text { transplant }\end{array}$ & 2009 & Medellin \\
\hline First cardiac retransplant & 2010 & Medellin \\
\hline $\begin{array}{l}\text { First left ventricular assist device } \\
\text { implantation }\end{array}$ & 2014 & Bucaramanga \\
\hline $\begin{array}{l}\text { Video-assisted thoracoscopic cardiac } \\
\text { denervation for refractory } \\
\text { ventricular arrhythmias }\end{array}$ & 2016 & Bogota \\
\hline First heart autotransplantation & 2017 & Bogota \\
\hline First robot-assisted cardiac surgery & 2017 & Bogota \\
\hline
\end{tabular}

heart transplant came just in time following those 2 important national tragedies and paved the way to a bright future in cardiovascular surgery unexpected by many. Worth mentioning, this heart transplant team from Medellin followed techniques learned at Stanford University through traveling fellowships. Colombia was the third Latin American country to perform cardiac transplants. ${ }^{3,4}$ Colombia's first heart transplant was performed 18 years after the world's first heart transplant performed on December 3, 1967, by Dr Christiaan Barnard in South Africa. In October 1997, this same surgical team would perform the country's first lung transplantation. In January 2009, they once again amazed with the country's first simultaneous cardiac and lung transplantation on a 15 -year-old patient with Eisenmenger syndrome. In May 2010, they performed the first cardiac retransplantation in a 13 -year-old patient. ${ }^{3,4}$ By their 25th heart transplant anniversary, the Clínica Cardiovascular Santa Maria (today "Cardiovid") in Medellin had performed more than 316 heart transplants and 58 lung transplants. By 2018, they documented more than 500. In 1996, Bogota established its first transplant department at the Fundación Clínica Shaio, and in 2017 the first heart autotransplantation was performed on a 22-year-old female patient to remove a cardiac paraganglioma. This procedure, performed at the Fundación Cardioinfantil in Bogota, was the first heart autotransplantation in Latin America. Today, at a major referral center in Cali, with a developing lung transplant department, transplantation is assisted by a female cardiovascular surgeon (Dr Martha Giraldo), and most major cities in Colombia now have functioning cardiac transplantation departments.

On September 21, 2017, the first robot-assisted cardiac surgery (RACS) in Colombia was performed at the Fundación Clínica Shaio Heart Institute using a da Vinci $\mathrm{Xi}$ console (Intuitive, Sunnyvale, Calif). To date, this institute is the only center in Colombia performing RACS. The first procedures were mitral valve repairs and atrial septal defects. Today, this same clinic has the most advanced extracorporeal membrane oxygenation (ECMO) department in Bogota.

\section{COLOMBIAN CARDIAC SURGERY TRAINING PROGRAMS}

During the 1950s, before Colombia had cardiac surgery training programs, surgeons who desired cardiovascular surgery training would go abroad to learn cardiac surgery. Most of them became cardiovascular surgeons immediately after medical school, skipping general surgery training. An important example of this is Dr Alberto Villegas, who obtained his cardiac surgery training at King's College University in England and later in Washington. Today, in Colombia, cardiovascular surgery residencies follow general surgery training; there are no cardiac surgery tracks straight from medical school or combined cardiothoracic surgery tracks. Colombia has 6 different cardiovascular surgery residency programs, all at medical schools/universities, as well as a general thoracic surgery program based in Bogota (Table 2). Two of these cardiac surgery programs are located in Medellin, and the other 4 are in Bogota. ${ }^{1}$

\section{Admissions/Recruitment Process}

Prerequisites for applying to a cardiac/cardiovascular surgery training program in Colombia include a general surgery degree, whether obtained in Colombia or internationally. In The Netherlands, for example, cardiothoracic 
TABLE 2. Cardiovascular surgery residency programs in Colombia

\begin{tabular}{|c|c|c|c|c|c|}
\hline & University/medical school & Duration & Location & Prerequisite training & Title awarded \\
\hline 1 & Universidad Pontificia Bolivariana (UPB)-Cardiovid & $2.5 \mathrm{y}$ & Medellin & General surgery & Cardiovascular surgeon \\
\hline 2 & Universidad CES & $3 y$ & Medellin & General surgery & Cardiovascular surgeon \\
\hline 3 & Pontificia Universidad Javeriana (PUJ)-Fundación Clínica Shaio & $2 y$ & Bogota & General surgery & Cardiovascular surgeon \\
\hline 4 & Universidad del Rosario- Fundación Cardioinfantil (FCI) & $3 y$ & Bogota & General surgery & Cardiovascular surgeon \\
\hline 5 & Universidad Militar Nueva Granada & $3 y$ & Bogota & General surgery & Cardiovascular surgeon \\
\hline 6 & FUCS & $3 y$ & Bogota & General surgery & Cardiovascular surgeon \\
\hline
\end{tabular}

training is done as a 5- to 6-year integrated residency straight from medical school. In the United States, both integrated 6-year programs and traditional tracks (following general surgery) are available. Admissions exams are generally multiple choice-based, and interviews follow once the required passing grade is achieved. These exams are generally written and include general medicine, general surgery, and cardiovascular surgery questions. The admissions exam passing rate is roughly $20 \%$ to $40 \%$, with variation among programs. The 6 Colombian programs accept 1 to 2 residents per year based on their $\mathrm{CV}$ score, professional merits, exam results, surgery experience, publications, and English-speaking skills. In the event that any 1 of the 6 programs cannot find a suitable candidate for its training program, it has the right to deny residency admissions for that academic year. The 6 different residency programs have a duration of 2 to 3 years, depending on the school's specific criteria and the program's hour intensity, nonclinical training, and surgery exposure. An established number of procedures required by each resident in each academic year is still not standardized in Colombia, and training hours vary across the programs. The main areas of training include valve surgery, coronary surgery, aortic and great vessel surgery, congenital cardiac surgery, arrhythmia surgery, hemodynamics, cardiac imaging, ECMO, transplantation, robotics, and cardiac intensive care. Table 3 provides general information on the 6 programs and is not specific to any single curriculum. Cardiac surgery rotations are based at each school's private training center, and elective rotations are available at external centers. During their cardiac surgery residency, trainees do not rotate in general thoracic surgery. A resident who desires general thoracic surgery exposure must request an elective rotation. In Colombia, general thoracic and cardiovascular surgery are not integrated into a single curriculum. ${ }^{1,5}$

Because most Colombian cardiac surgery program directors and professors have had significant international training in the United States and other countries, through either traveling fellowships or formal residencies, each program has certain characteristics and is structured partially based on US and other international cardiovascular surgery programs. The primary difference is the exclusion of general thoracic surgery training. Colombian surgeons have obtained international cardiovascular surgery degrees in such locations as São Paulo, Brazil, Buenos Aires, Argentina, Barcelona, Spain, and Stanford, California (Dr Juan Pablo Umaña). Of note, Dr Umaña became one of the pioneers in "bow-tie" mitral valve repairs during his time in the United States. ${ }^{6}$ Other international/traveling fellowship locations and institutes visited by Colombian surgeons include Baylor University, New Jersey, Cleveland Clinic, Mount Sinai Medical Center, and University of Alabama.

\section{Traditional Cardiac Surgery Track Design}

In Colombia, the prerequisite training in general surgery provides residents with a strong foundation in thoracic trauma. Because of the extremely high rates of penetrating thoracic and cardiac trauma in the country, most general surgeons naturally become well trained in trauma and are generally considered "nontitled" trauma surgeons. Currently, Colombia has only a single 2-year acute care and trauma surgery fellowship program for general surgeons, based in Cali. In Colombia, the only cardiovascular surgery track design is a 2- to 3-year curriculum following general surgery. This allows residents to develop a strong foundation in thoracic trauma during their general surgery training, equipping them with important acute-care surgical criteria that are later vital when caring for cardiac surgical patients. In Colombia as well as certain other countries, cardiothoracic instructors favor tracks following general surgery (traditional tracks) over the newer "integrated" tracks because of the skills residents acquire during general surgery. 5,7

\section{YOUNG SURGEONS' PERCEPTIONS}

In Colombia, young general surgeons interested in chest surgery can choose between general thoracic and 
TABLE 3. General track design, curriculum structure, and characteristics of Colombian cardiac surgery programs

\begin{tabular}{|c|c|c|c|}
\hline Rotation & $\begin{array}{l}\text { Approximate } \\
\text { duration }\end{array}$ & $\begin{array}{l}\text { Approximate } \\
\text { intensity }\end{array}$ & Location/hospitals \\
\hline \multicolumn{4}{|l|}{ Pediatric cardiac } \\
\hline Congenital and pediatric heart surgery & $6-9 \mathrm{mo}$ & $1042-2880 \mathrm{~h}$ & Bogota/Medellin at private university hospitals \\
\hline Adult cardiac & & $4465-5760 \mathrm{~h}$ & \\
\hline Coronary heart surgery & $12 \mathrm{mo}$ & $740 \mathrm{~h}$ (varies) & Bogota/Medellin at private university hospitals \\
\hline Valve surgery & $12 \mathrm{mo}$ & $578 \mathrm{~h}$ (varies) & Bogota/Medellin at private university hospitals \\
\hline Arrhythmia surgery & $1 \mathrm{mo}$ & $144 \mathrm{~h}$ & Bogota/Medellin at private university hospitals \\
\hline Great vessel and vascular surgery & $6 \mathrm{mo}$ & $432 \mathrm{~h}$ & Bogota/Medellin at private university hospitals \\
\hline Transplantation & Relative & Varies & Bogota/Medellin at private university hospitals \\
\hline \multicolumn{4}{|l|}{ Cardiology and imaging } \\
\hline Hemodynamics, cardiology, and Echocardiography & $3-4 \mathrm{mo}$ & $1598 \mathrm{~h}$ (varies) & Bogota/Medellin at private university hospitals \\
\hline Cardiac ICU and anesthesia & $2 \mathrm{mo}$ & $360-520 \mathrm{~h}$ & Bogota/Medellin at private university hospitals \\
\hline ECMO & $1 \mathrm{mo}$ & Varies & Bogota/Medellin at private university hospitals \\
\hline \multicolumn{4}{|l|}{ Others } \\
\hline Elective & $3 \mathrm{mo}$ & $650-720 \mathrm{~h}$ & Resident's choice \\
\hline Robotic cardiac surgery & Relative & Relative & Shaio (Bogota) \\
\hline Clinical Research & Continuous & $150-300 \mathrm{~h}$ & Bogota/Medellin at private university hospitals \\
\hline
\end{tabular}

This table represents the approximate combined structure and general design of all 6 programs and is not specific to any single training program.

cardiovascular surgery. A young surgeon choosing cardiovascular surgery and wishing to pursue a career in this field must consider various factors before applying to any of the 6 programs. In Colombia, fellowship programs (subspecialties) are generally not financially reimbursed; thus, external financial support is critical to residents who aspire to these programs. In the United States and Europe, residents receive reimbursements from the hospitals in which they practice, whereas in Colombia this is still not nationally established, resulting in a financial burden for doctors in training. Residency spots are opened once yearly, and are limited and thus highly sought after and competitive. Cardiovascular training programs are based at renowned, state-of-the-art teaching centers with high complexity and patient volume. Each of these centers has a preference for its own residents. Thus, choosing the right program also implies having a greater chance of working at that center in the future; this generally applies in other countries as well.

Each cardiovascular department in Colombia has its own specific area of expertise. Some hospitals and clinics focus on minimally invasive cardiovascular surgery, others on robotic cardiac surgery, heart transplantation, or congenital/pediatric cardiac surgery, and some have experience caring for international patients. Most aspiring residents choose training programs based on the training centers and hospitals in which they will rotate. For instance, UPB-Cardiovid has the largest volume of transplantation, PUJ-Shaio has the only robotic heart surgery training exposure, and FCI-Rosario focuses on congenital cardiac surgery. One possible pitfall resulting from this system is the lack of exposure to highly specialized centers for each area. A solution may be to allow residents to rotate in specific departments at external centers specialized in each of these areas, and perhaps create a resident interchange network.

Another possible way cardiothoracic surgery residency programs may improve is perhaps by following the newer Dutch model. In 2018, The Netherlands Society for Thoracic Surgery modified their national training curriculum slightly. The newer model allows residents to choose the rotations apart from the basic compulsory rotations of cardiothoracic surgery and thus design and structure a more personalized residency experience, letting them quickly focus on special areas.

\section{ORGANIZATION AND CARDIAC SURGERY PRACTICE FOLLOWING TRAINING}

Board certification is obtained once all the established requisites of each university are completed. In Colombia, board certification is acquired as part of the national licensing process and the cardiac surgery title award by each university, with no additional exams required. General surgeons from Colombia who already have a practicing license may commence work as a certified cardiac surgeon on completion of training. International general surgeons must obtain a Colombian medical license. Cardiovascular surgeons who graduate from international programs and desire to practice in Colombia must fulfill some requirements. The cardiac surgery degrees offered in Colombia 
are given by medical schools/universities; therefore, to practice with an international degree, surgeons must obtain a Colombian medical license. Some Latin American programs are institution/hospital-based and not associated with a medical school. This poses a dilemma, because Colombian cardiovascular surgery certification and licensing requires that titles be awarded by a registered medical school, and hospital-based degrees generally are not accepted. Transferring credentials and obtaining board accreditation requires an administrative process through the Colombian Health Ministry.

The primary concern of young cardiovascular surgery residents is finding a practice after finalizing training. In Colombia, cardiovascular surgeon turnover is slow. Up to 10 general surgeons apply yearly to each of the 6 programs, and not all the residency spots are filled every year. According to international statistics, there is a growing worldwide deficit of cardiothoracic surgeons. Reported reasons for this include training intensity, years of residency, age at board certification (average 36.6 years), and availability of practice spots following training. As a result, younger surgeons have become less attracted to cardiac surgery compared with other surgical subspecialties. ${ }^{5,8,9}$ In Colombia, the main reason for the low number of applicants is the scarcity of positions after residency; most cardiovascular positions in the country are already occupied. Approximately 4 to 6 attending cardiovascular surgeons are staffed at each certified cardiac surgery center in Colombia. To find work following training, young cardiac surgeons need to quickly become associated with a cardiovascular surgery team. This problem is also shared with cardiovascular surgery practices in different parts of the world. ${ }^{8,9}$ Residency vacancies result in these programs becoming an interesting option for international candidates who wish to train in Colombia and later return to their country of origin. In Colombia, cardiac surgeons work in group practices hired by hospitals and private clinics. A young aspiring surgeon who does not have a secured practice spot following training risks remaining without an attending position following residency. This problem is not easily solved, given that cardiac surgeons can only practice cardiac surgery at centers with an infrastructure that supports an entire cardiovascular team.

In Colombia, cardiac surgeons can join the Colombian Association of Cardiology and Cardiovascular Surgery. This association has its own journal, Revista Colombiana de Cardiología. The association was founded in Bogota on September 18, 1943, and the journal was born in 1961. Some cardiac surgeons in Colombia are also members of the Society of Thoracic Surgeons (STS) and European Association of Cardiothoracic Surgery (EACTS). In 2017, the STS and EACTS organized the first Latin America Cardiovascular Surgery Conference, held in Cartagena, Colombia and led by Dr Juan Pablo Umaña. Today, this conference is held annually in different cities in Latin America and represents an important advancement in Latin American and Colombian cardiac surgery.

Colombian cardiovascular surgery and centers also play an important role in Latin American and Caribbean health systems. Many regions of the world lack direct access to cardiac surgical care; at the moment, more than 4 billion people have no direct access to a cardiothoracic center. ${ }^{10}$ Colombian cardiovascular surgery institutes help fill these gaps by caring for many international patients. For example, the Caribbean island of Aruba (Dutch Antilles), which does not have cardiothoracic surgeons, transfers more than 150 cardiac patients a year to different centers in Colombia for both urgent and elective cardiac care.

\section{CONCLUSIONS}

How cardiac surgery residency programs and cardiovascular surgery practice are structured in Colombia is based in part on, and has certain characteristics adapted from, North American cardiac surgical education and practice. This influence and impact have been critical and fundamental, and we extend our gratitude to our North American colleagues, pioneers, and centers for their contributions to our country. In Colombia, cardiovascular surgery and training will keep advancing, following the footsteps of North American and European standards of care.

I thank Drs Camilo Osorio Barker, Víctor Caicedo, Javier Maldonado, Carlos A. Arias, and Federico Núñez for their contributions to this article.

\section{References}

1. Vinck EE. General thoracic surgery as a subspecialty in Colombia. J Thorac Cardiovasc Surg. 2019;157:2542-6.

2. Glenn WW, Patiño JF. Circulatory by-pass of the right heart. I. Preliminary observations on the direct delivery of vena caval blood into the pulmonary arterial circulation; azygos vein-pulmonary artery shunt. Yale J Biol Med. 1954;27: 147-51.

3. Clínica Cardiovascular Congregación Mariana. La Palpitante Historia de un Trasplante. Colombia: Medellín; 2010.

4. Lozano G. Historia de la cardiología en Colombia. Acta Med Colomb. 1989;14: 41-7 (in Spanish)

5. Tchantchaleishvili V, Mokashi SA, Rajab TK, Bolman RM 3rd, Chen FY, Schmitto JD. Comparison of cardiothoracic surgery training in USA and Germany. J Cardiothorac Surg. 2010;5:118.

6. Umaña JP, Salehizadeh B, DeRose JJ Jr, Nahar T, Lotvin A, Homma S, et al "Bow-tie" mitral valve repair: an adjuvant technique for ischemic mitral regurgitation. Ann Thorac Surg. 1998;66:1640-6.

7. Keilin CA, Sandhu G, Matusko N, Reddy RM. Ten years into the integrated residency era: a pilot study shows many cardiothoracic surgery faculty still favor the traditional pathway. Semin Thorac Cardiovasc Surg. July 11, 2019 [Epub ahead of print].

8. Salazar JD, Ermis P, Laudito A, Lee R, Wheatley GH 3rd, Paul S, et al. Cardiothoracic surgery resident education: update on resident recruitment and job placement. Ann Thorac Surg. 2006;82:1160-5. 
9. Sterbling HM, Molena D, Rao SR, Stein SL, Litle VR. Initial report on young cardiothoracic surgeons' first job: from searching to securing and the gaps in between. J Thorac Cardiovasc Surg. 2019;158:632-41.e3.
10. Vervoort D, Meuris B, Meyns B, Verbrugghe P. Global cardiac surgery: access to cardiac surgical care around the world. J Thorac Cardiovasc Surg. 2020;159: 987-96.e6. 